\title{
REPETITIVE MANUAL OPERATIONS IN THE DAIRY SECTOR: ANALYSES AND CRITERIA FOR INTERVENTION
}

\author{
Pier Riccardo Porceddu, Laura Rosati
}

\section{Introduction}

The social-economic development of European countries has determined increasing well-being for its populations, and also the greater attention that is being paid to aspects of safety of products and for workers involved in production. In Europe the main directive regarding health and safety of workers at work was the n. 391 of 12th June 1989 "On the introduction of measures to encourage improvements in the safety and health of workers at work", which in Italy was acknowledged by the Legislative Decree n. 626 of 19th September 1994.

Innovations at a structural and organizational level, introduced by the Decree n. 626, have effectively led to an overall drop, over the last ten years, of the number of injuries and professional diseases. However, although there has been a drop in "traditional" pathologies, such as noise deafness, there has been a disturbing increase of musculoskeletal disorders, caused mainly by the lifting and transport of heavy weights, wrong working positions (extreme postures and/or sudden movements) and repetitive movements [7].

They are, above all the latter, more insidious, less audible and visible risk factors, but nevertheless present, and depend, in most cases, on an inadequate organization of work [2]. The seriousness of the phenomenon has not been underestimated, and in the last ten years, especially in the United States and in Europe, various evaluation models of the risk of repetitive movements have been elaborated, by authoritative organizations such as the NIOSH (National Institute of Occupational Safety and Health), OSHA (Occupational Safety \& Health Administration) [8], ACGIH (American Conference of Governmental Industrial Hygienists) [1], INRS (Institut National de Recherche et de Sécurité) and the EPM Unit (Er-

Paper received 7.11.2006; accepted 14.02.2008

Dr. Pier Riccardo Porceddu, Researcher. Dr. Laura Rosati, Grant student. Dept. of Agricultural and Environmental Sciences, University of Perugia, porceddu@agr.unipg.it

Authors contributed equally to the research. gonomics of Posture and Movement) at the University of Milan [5].

The models applied can be conveniently divided into three levels as a function of the accuracy with which they deal with the problem. Particularly, 1st level methods are exclusively utilised to identify repetitive movements during work activity through the adoption of risk indicators such as: performing the same movement repetitively in a short time period; a repetitive use of hand force; extreme movement or posture of the wrist or shoulders. If any of these movements are present 2 nd level methods are adopted to identify repetitive duties, work cycles, risk factors and body members involved (hands, wrists, arms, shoulders). Once the risk in developing musculoskeletal injuries has been identified and related to work activities, the evaluation of the problem can proceed by means of 3rd level methods. These are based on a detailed analysis of the different operations. This involves the use of video cameras that allow studying movements in more details, even by means of slowmotion. These methods also enable the quantification of risk through adequate indices, as well as the possibility of reorganizing the work place and directly evaluating the resulting benefits.

The main analysis models are: Check-list of the OSHA (1st level); TLV of the ACGIH (2nd level); Strain Index of the NIOSH, OREGE of the INRS, OCRA of the EPM (3rd level methods).

In the agro-industrial sector there are many activities whose productive rhythms are urgent and cause notable exposure to bio-mechanic risk factors.

This is the case of the dairy sector, in which the production and processing of milk follows a series of successive steps, which cannot be delayed. The workers are subject to a number of biomechanical risks and to carrying out repetitive movements, so much so that some of the operations require a degree of strength.

These risk factors, which are reduced in industrial dairies due to the total or partial automation of the various working phases, are however present in artisan dairies, which are often family managed and have a limited amount of technology and mechanization of the work. 
In the Region of Umbria alone there are 28 dairies. Apart from 5 of them, which can be considered industrial dairies, all the others are small productive units, producing less than $10^{4} \mathrm{~kg}$ of milk per day, and with only partial automation of the productive phases. In each of these units there are on average less than 10 workers and they are usually family managed.

For this typology of dairy a thorough study of the exposure of workers to repetitive manual movements has been carried out, so as to determine the necessary measures to reduce the risk factors and plan safety measures.

\section{Materials and methods}

In order to evaluate the risk of repetitive manual operations, all the various phases and tasks carried out by each worker in a dairy of the Region of Umbria were analysed. These analyses were carried out directly in the workplace, using film, which could then be re-seen as many times as necessary, to examine the detail of repetitive operations carried out by the workers. They were then analysed using OCRA method.

\subsection{Description of the dairy and the activities carried out}

The study was carried out in a family managed dairy, with 6 workers, that processes a daily quantity of milk of around $8500 \mathrm{~kg}$. The working timetable includes 8 hours per day for five days a week, while Saturday and Sunday are devoted to receiving supplies of milk and stocking it.

The products it produces are: about $2700 \mathrm{moz}-$ zarellas per day (70\% of the entire production); ricotta and butter; soft cheeses, hard cheeses, stringy cheeses. The production phases are:

Milk supply and stocking. The milk arrives at the dairy in refrigerated tankers, and is then filtered to remove impurities and stocked in refrigerated silos;

Preliminary treatment. The preliminary treatment consists of the process of pasteurization: heating the milk up to $72{ }^{\circ} \mathrm{C}$ and maintaining the temperature for around 30 seconds.

Production of soft and hard cheeses. The milk, heated during pasteurization, is transferred into multipurpose boilers, lactic yeast and rennet are added; a slow mixing process follows, until the curd is formed, which is then cut into small cubes with rotating blades, inside the multi-purpose boiler. Then the excess whey is eliminated through the use of pumps, and the curd is unloaded manually onto steel trolleys. It is then placed in appropriate perforated moulds and turned over many times, in order to drain off the remaining whey and to give the cheeses their desired shape.

Production of stringy cheeses. The curd extracted from the boilers is mainly used to produce stringy cheese and in particular mozzarellas. The process requires a "stringing" machine, into which the curd is inserted manually, after being cut with an appropriate knife.

Production of ricotta. The whey coming from the filtering of the curds is put in boilers with double bottoms and steam heated. The coagulated mass which rises to the surface is left to solidify and then the ricotta is collected with a perforated ladle and put into plastic bags.

Production of butter. Butter-making requires the beating of the cream with a churn, the extracting of the milky solution, the washing of the butter and kneading. The butter is packaged in small blocks using an appropriate cutting machine.

Steam heating of hard and soft cheeses. The workers, after having compacted the curds in the appropriate moulds, put them in heated chambers or steaming blocks, to facilitate a last draining. The cheeses are turned over several times in the heated chambers.

Salting. Both hard and soft cheeses and stringy cheeses are then immersed in tanks with saline solutions, where they are left for a period of time depending on the kind of end product desired.

Storing, maturing and conditioning. The salted cheeses are next stocked in the maturing area, from which they are periodically extracted for cleaning with appropriate brushing machines, with the aim of removing mould which forms on their surface.

Packing. The blocks of butter are wrapped manually and then stocked in refrigerators. The mozzarellas are first packed one by one by machine, and then put into plastic bags, ready for sale.

Sanification. The operations of daily sanification are carried out manually with the help of long brushes and sprays and often require that parts of the machinery be dismantled, such as for example the cleaning of "kneading" and "stringing" machines.

\subsection{The OCRA method}

In order to evaluate exposure to risk of repetitive movements, the OCRA (Occupational Repetitive Actions) method has been adopted [4], which is used for the close analysis of the ergonomics of working positions, and to re-programme them.

This method of analysis is based on a procedure which can be applied to repetitive jobs, which involve the consecutive execution, for at least one hour a day, of working cycles which are similar among themselves, of relatively short (a few minutes) length, which require mechanical technical actions carried out by the upper limbs. It is a quantitative method which takes into consideration 5 variables or risk factors: repetitiveness (expressed as the frequency of technical actions carried out in the unit of time), applied strength, extreme postures and/or incongruous movements, complementary risk factors (vibrations, high or low temperatures, localized compressions...) and the absence of rest periods. Each of these variables is opportunely evaluated and quantified, with the aim of obtaining an exposure index (I.E.), the ex- 
pression of the risk to workers who carry out consecutively, during their shift, repetitive cycles of mechanical technical actions for at least 1 hour

$$
\text { I.E. }=\mathrm{Ae} / \mathrm{Ar}
$$

where:

Ae: the total number of actions effectively carried out considering all the repetitive tasks examined. For the calculation of Ae it is necessary to determine for each worker the tasks which have a consecutive duration of more than 1 hour, which include repetitive movements (technical actions). These technical actions are identified and defined, quantified for the chosen unit of time and multiplied to express a value for the whole time of the task. In this way the value Ae is reached for the upper limbs. Ar: the total number of "recommended" technical actions for the work shift under examination:

where:

$$
\mathrm{Ar}=\{[\mathrm{CF} \times \mathrm{Ff} i \times \mathrm{Fp} i \times \mathrm{Fc} i \times \mathrm{D} i]\} \times \mathrm{Fr}
$$

$i(1 \ldots n)$ : the task/s with repetitive movements of the upper limbs during the shift;

CF: the frequency constant of technical actions per minute, recommended in optimal work conditions. This regards, as far as tasks including repetitive movements are concerned, the variable which most characterizes the exposure to risk. In optimal work conditions, in which other risk factors are not influential or not very significant, the most suitable frequency constant is fixed at 30 technical actions per minute.

Ff: strength risk factor, ranging between 0 and 1 , evaluated for each of the number of repetitive tasks carried out and quantified using the Borg scale. The strength used during a working task is linked both to the movement and/or maintenance of work instruments and tools, and to the adopting of a specific position for part of the body. To quantify this strength Borg's scale is used (Category Scale for Rating of Perceived Exertion) (tab. 1), which consists of 10 points and is able to describe perceived muscular strength for a given part of the body, implicated in the carrying out of a specific working task. Operationally the actions requiring strength are identified and the worker is asked to attribute to each of them a mark of $0-10$, on the basis of the Borg scale. With reference to the duration of each technical action and corresponding to each working task, a pondered average value is calculated for each of the upper limbs. Lastly for the calculation of $\mathrm{Ff}$ a conversion table is used (tab. 2).

Fp: the risk factor of posture and/or extreme movements, between 0 and 1 , evaluated using reports drawn up by the CEN. Through observation of a cycle, both directly and on a film reseen in slow-motion, movements and/or postures of the shoulder region, elbow, wrist and hand (kind of hold and finger movements) for both arms are described (tab. 3). In this report are included the so-called "risk" areas, which determine the going above the $40-50 \%$ of the respective maximum range of the joint extension. For each risk area a score is given, which is 0 if during the repetitive operation analyzed, the upper limbs don't carry out movements in that area, or 2, 4, 6, 8, 12, 24 if the contrary is true. Moreover it is possible to register the length of this movement $(1 / 3,2 / 3,3 / 3$ of the cycle time). In this way the possible presence of similar joint movements can be shown, identifiable through the observation of technical actions of the same kind (independently from the range of joint extension) for at least $2 / 3$ of the cycle time, and also the presence of static positions which are maintained equal to themselves for at least $2 / 3$ of the same time cycle. Finally the calculation of the total score of muscular use is made, within the representative cycle, and characterizing the repetitive task examined. In particular the value used as reference for a given repetitive task is the most penalizing (the highest). Lastly, to calculate the Fp, a conversion table is used (tab. 4).

Fc: risk factor of complementary elements, from 0 to 1 . For the description of these elements the same information methods (direct observation and slowmotion filming) and table 5 are used. In this table the most frequent complementary factors are listed, with

\begin{tabular}{|c|c|c|c|c|c|c|c|c|c|c|c|c|}
\hline Effort & $\begin{array}{l}\overrightarrow{0} \\
\text { D } \\
\text { त्ठ }\end{array}$ & 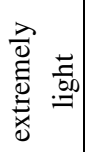 & 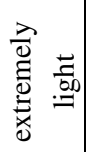 & 苛 & 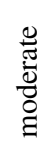 & 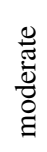 & 占 & $\begin{array}{l}\infty \\
\stackrel{0}{0} \\
\stackrel{\Xi}{\infty}\end{array}$ & 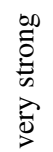 & 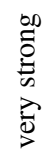 & 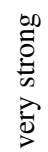 & 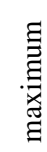 \\
\hline Points & 0 & 0.5 & 1 & 2 & 3 & 4 & 5 & 6 & 7 & 8 & 9 & 10 \\
\hline
\end{tabular}
the possibility of adding others.

TABLE 1 - Borg scale.

\begin{tabular}{|c|c|c|c|c|c|c|c|c|c|c|}
\hline $\begin{array}{c}\text { Average perceived effort } \\
\text { according to Borg }\end{array}$ & $\geq 0.5$ & 1 & 1.5 & 2 & 2.5 & 3 & 3.5 & 4 & 4.5 & $\leq 5$ \\
\hline Multiplicative factor & 1.00 & 0.85 & 0.75 & 0.65 & 0.55 & 0.45 & 0.35 & 0.20 & 0.10 & 0.01 \\
\hline
\end{tabular}

TABLE 2 - Conversion table for the value indicating effort, in the respective multiplicative factor. Generally there are no technical actions which require physical strength above 5 on the Borg scale. 
As in the evaluation of the postural use, the risk of the presence of complementary factors is synthesized in a single code which provides the value of the index of complementary elements, from which it is possible to calculate the Fc (tab. 6).

$\mathrm{D} i$ : length in minutes, of each of the $n$ of repetitive tasks;

Fr: multiplicative factor of the risk of "lack of recovery time", from 0 to 1 , chosen in relation to the number of hours carried out without adequate recovery time (calculated for the entire work shift).

Breaks and lunch breaks are considered recovery times, as are periods during which the muscular groups previously involved are substantially rested.
Within the first hour of work with repetitive tasks, at least 10 minutes rest are necessary. For the evaluation of Fr it is necessary to know exactly the times of the work shifts, the length of the repetitive tasks and of the breaks, and to use the appropriate conversion table (tab. 7).

From the ratio between Ae and Ar the index of I.E. exposure is obtained. For I.E. $<0.75$ of fully acceptable work activity, as carried out by the worker. For $0.75 \leq$ I.E. $\leq 4.00$ risk-involving task (area of uncertainty). Therefore the possible effects and safety risks should be actively monitored. For I.E. $>4.00$ the work activity is unacceptable.

Improvement in working conditions and safety monitoring must be introduced.

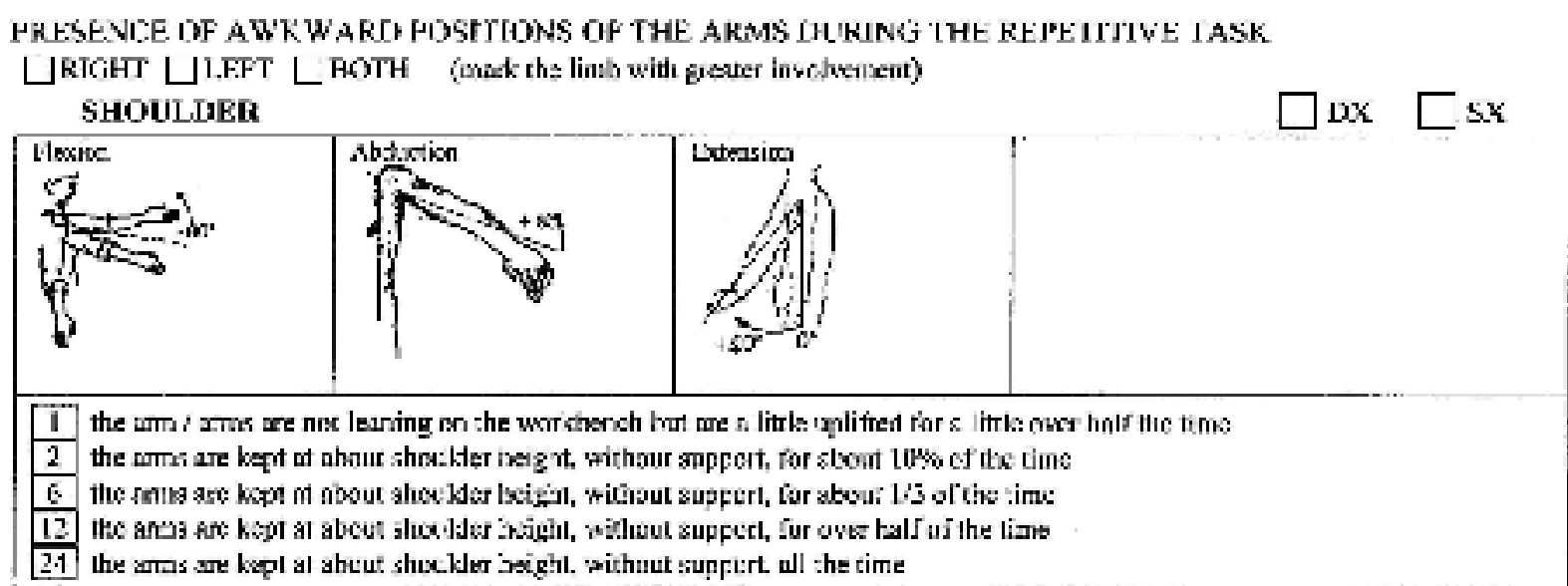

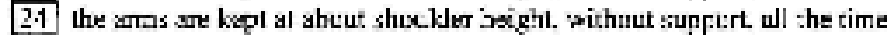

F.LAOW

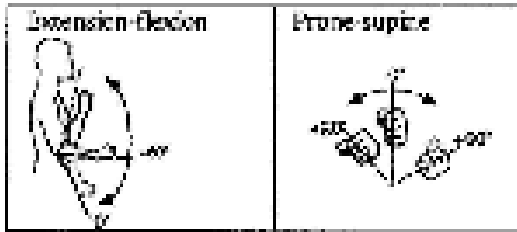

H'RIST
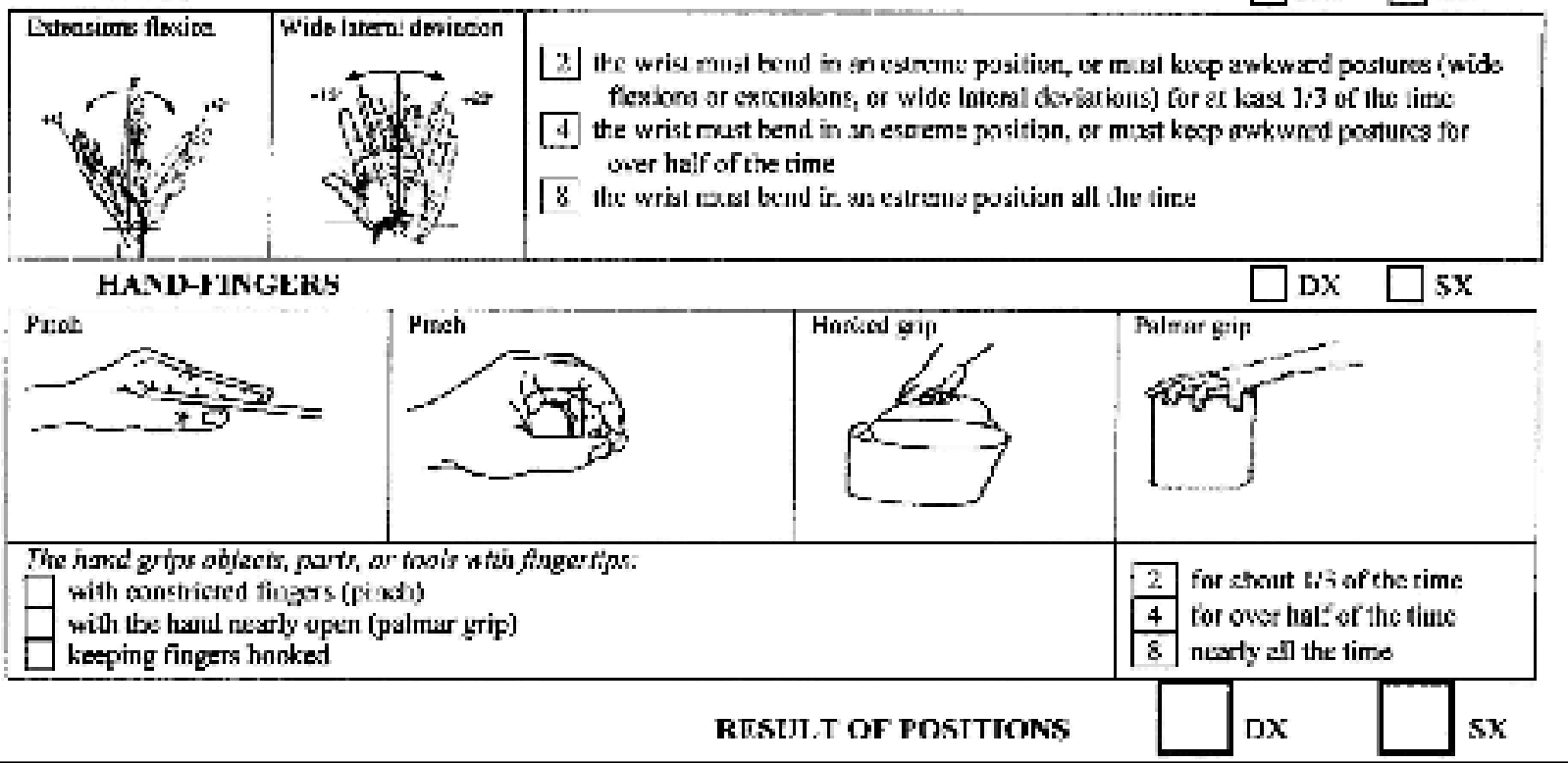

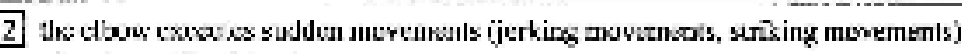

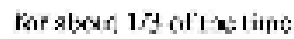

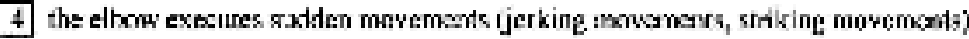
for cover half of the rime

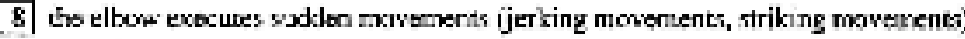
nisurly all tive time

2. Ite wris mull bend in tro esdrone pusitivn, ue m.tsl kuxp ankward postures ínids

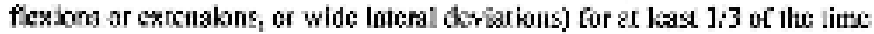

4 the wrist rust bend in .an esceme position, or mixt kecp awkwnd postures for vier half of the rime

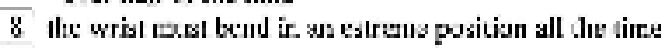




\begin{tabular}{|l|c|c|c|c|c|c|c|c|}
\hline Value of the index of the postural task & $0-3$ & $4-7$ & $8-11$ & $12-15$ & $16-19$ & $20-23$ & $24-27$ & $\geq 28$ \\
\hline Multiplicative factor & 1.00 & 0.70 & 0.60 & 0.50 & 0.33 & 0.10 & 0.07 & 0.03 \\
\hline
\end{tabular}

TABLE 4 - Elements to shift from the descriptive value of the posture use to a corresponding value of the multiplicative factor.

PRESENCE OF ADDITIONAL RISK FACTORS (only choose one answer per group of questions)

2 gloves inadequate to the task are used for over half of the time (uncomfortable, too thick, wrong size, etc.)

2 vibrating tools are used for about $1 / 3$ of the time

2 the tools employed cause compressions of the skin (reddening, callosities, etc.)

2 precision tasks are carried out for over half of the time (tasks over areas smaller than 2 or $3 \mathrm{~mm}$ )

2 more than one additional factor is present at the same time and, overall, they occupy over half of the time

3 one or more additional factors are present, and they occupy the whole of the time

1 working pace set by the machine, but there are buffers in which the working rhythm can either be slowed down or accelerated

2 working pace completely determined by the machine

RESULT

DX $\quad$ SX

TABLE 5 - Presence of additional risk factors.

\begin{tabular}{|l|c|c|c|c|c|}
\hline Value of the index of complementary elements & $0-3$ & $4-7$ & $8-11$ & $12-15$ & $\geq 16$ \\
\hline Multiplicative factor & 1.00 & 0.95 & 0.90 & 0.85 & 0.80 \\
\hline
\end{tabular}

TABLE 6 - Elements to shift from the descriptive value of the posture use to a corresponding value of the multiplicative factor.

\begin{tabular}{|l|c|c|c|c|c|c|c|c|c|}
\hline N. hours & 0 & 1 & 2 & 3 & 4 & 5 & 6 & 7 & 8 \\
\hline Multiplicative factor & 1.00 & 0.90 & 0.80 & 0.70 & 0.60 & 0.45 & 0.25 & 0.10 & 0.00 \\
\hline
\end{tabular}

TABLE 7 - Ratio between the hours and periods of rest.

\section{Results}

From the scrupulous analytic observation of the tasks carried out in the dairy it emerges that those activities which most involve risk are the preparation of ricotta and the packing of mozzarellas and blocks of butter (fig. 1, 2, 3, 4).

These operations are carried out in a period of over 1 hour, include repetitive movements, and moreover are carried out, in the studied dairy, by the same worker. Therefore all the times and tasks carried out during the whole day by the worker in question were recorded (tab. 8), and the various technical actions carried out in a cycle by the right and left arms were identified, together with the length and the number of products produced (tab. 9). The operation of the preparation of the ricotta consists of taking the forming ricotta from the double-bottomed boiler, with a perforated ladle, and positioning them in perforated tubs. It should be said that two different shapes of cheeses are produced, weighing 0.3 and 1.5 kilos, which determines a different number of technical actions; however, considering that the two shapes are produced in equal number, the mathematical average was considered. As far as concerns the packing of the

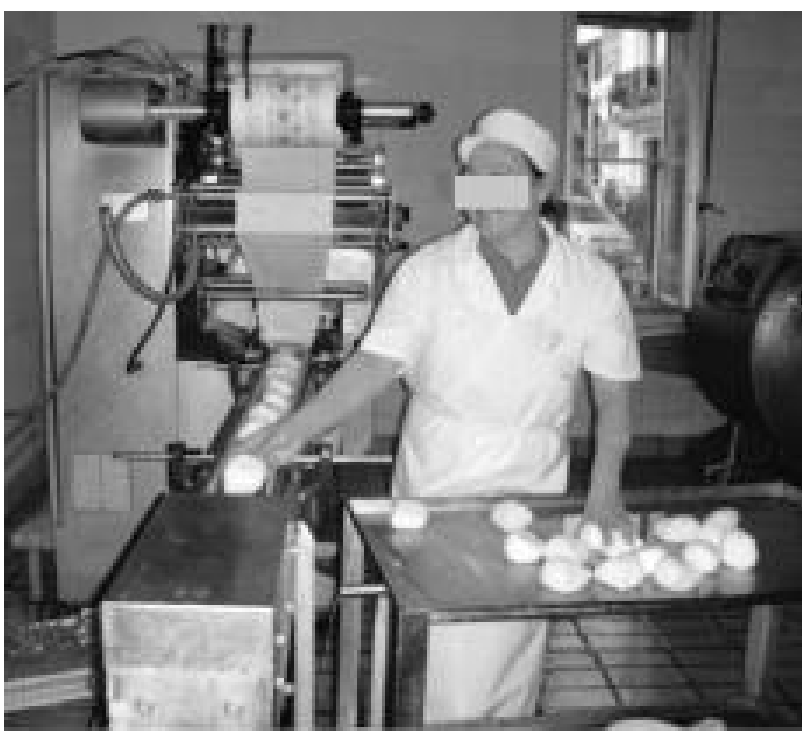

Fig. 1 - Positioning of mozzarellas on the conveyor-belt. The worker does too many movements. 


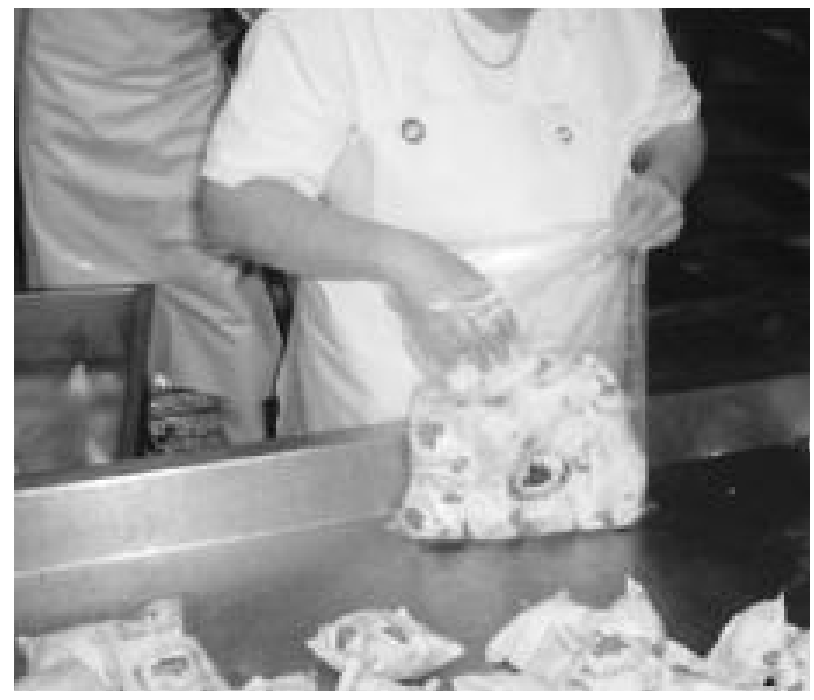

Fig. 2 - Preparation of 11 mozzarella packs. The worker uses the right arm much more than the left.

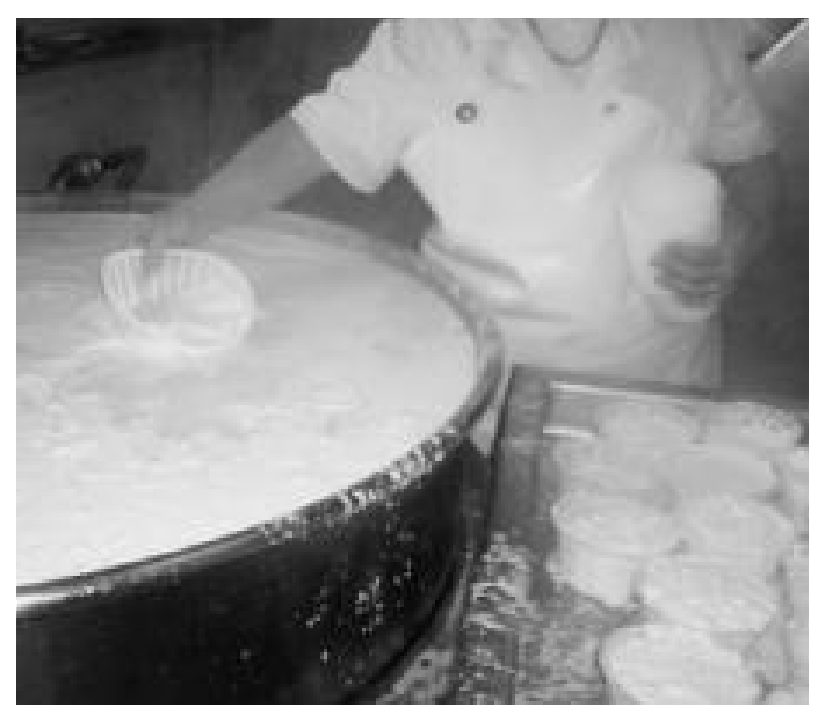

Fig. 3 - Putting the ricotta in colanders. The worker always uses the right arm.

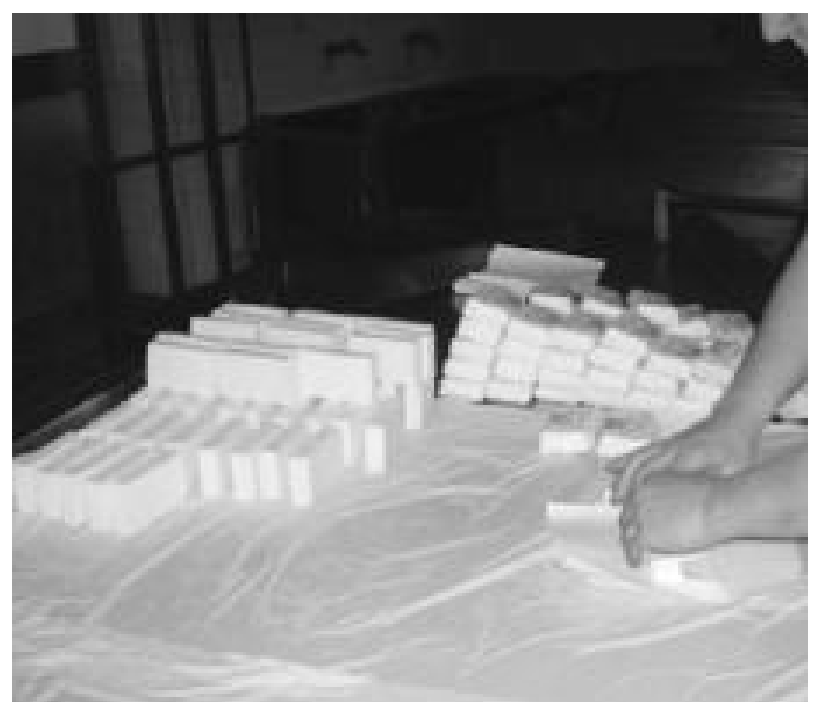

Fig. 4 - Packing blocks of butter. Each arm does the same number of movements.

\begin{tabular}{|l|c|}
\hline Task & Timetable \\
\hline A. Packing of blocks of butter & $7.00-8.30$ \\
\hline $\begin{array}{l}\text { B. Packing preparation for 11 mozzarellas } \\
\text { produced the previous day }\end{array}$ & $8.30-10.00$ \\
\hline P. Short break & $10.00-10.10$ \\
\hline C. Putting the ricotta in tubs & $10.10-11.40$ \\
\hline X. Cleaning operations & $11.40-12.00$ \\
\hline PM. Lunch break & $12.00-15.00$ \\
\hline $\begin{array}{l}\text { Y. Turning over of cheeses in the steaming } \\
\text { tank }\end{array}$ & $15.00-15.30$ \\
\hline $\begin{array}{l}\text { D. Position of the mozzarellas on the } \\
\text { conveyor belt }\end{array}$ & $15.30-17.00$ \\
\hline Z. Cleaning operations & $17.00-18.00$ \\
\hline
\end{tabular}

TABLE $\quad 8$ - Time distribution of tasks and pauses.

mozzarellas, they are wrapped one by one, using a packing machine. The worker has to be very quick in putting the mozzarellas on the conveyor belt (speed of $0.14 \mathrm{~m} / \mathrm{s}$ ), which takes them to the machine area, where they are wrapped. The operation is carried out in the afternoon for mozzarellas produced in the morning. The worker in charge of this operation, during the morning, carried out highly repetitive packing actions the same morning, regarding the preparation of 180 bags, each one containing 11 mozzarellas (which were wrapped, with the packing machine, during the afternoon of the day before). The blocks of butter are wrapped separately by the same person.

For the repetitive tasks A, B, C e D the Ae and Ar were calculated for each arm (tab. 10-11).

Consequently:

I.E. $=4.52$ for the right arm;

I.E. $=1.15$ for the left arm.

\section{Discussion and conclusions}

The analysis carried out has shown that the arranging of ricotta in tubs and the packing of mozzarellas and butter involve repetitive manual actions that can represent a risk. In particular it was shown that there was relevant exposure to risk for the right arm and a lower level of exposure for the left arm, which could lead, over a period of years, to muscolo-skeletal pathologies.

It is therefore necessary to re-plan the workplace. Such an operation is not always easy, since often it affects productivity, in order to safeguard the health of workers. It is also for this reason that safety is often perceived as a cost for a company. In the specific case, structural, organizational, training and information interventions can be proposed [3] [6]. Structural interventions include changes regarding the best organization of the workplace, furniture and layout. Such interventions tend to improve aspects linked to the excessive use of strength, posture, incongruous 


\begin{tabular}{|c|c|c|c|}
\hline \multicolumn{2}{|c|}{ Repetitive tasks } & Right arm & Left arm \\
\hline \multicolumn{4}{|c|}{ A. Packing of blocks of butter - One cycle corresponds to the packing of a block of butter } \\
\hline \multirow{5}{*}{$\begin{array}{l}\text { Technical } \\
\text { actions }\end{array}$} & 1. Take a block & & 1 \\
\hline & 2. Wrap the block & 3 & 3 \\
\hline & 3. Fold the remaining paper making two triangles & 2 & 2 \\
\hline & 4. Fold the triangles under the block & 1 & 1 \\
\hline & 5. Arrange the prepared blocks one above the other in line on the same table & 1 & \\
\hline \multicolumn{2}{|c|}{ Total technical actions in the cycle } & 7 & 7 \\
\hline \multicolumn{2}{|c|}{ Length cycle A [s] } & \multicolumn{2}{|c|}{10} \\
\hline \multicolumn{2}{|c|}{ Pieces produced per day $[\mathrm{n}]$} & \multicolumn{2}{|c|}{540} \\
\hline \multicolumn{4}{|c|}{ B. Preparation of 11 mozzarella packs - One cycle corresponds to the packing of a bag containing 11 mozzarella } \\
\hline \multirow{4}{*}{$\begin{array}{l}\text { Technical } \\
\text { actions }\end{array}$} & 1. Take the mozzarellas from the shelf one by one & 11 & \\
\hline & 2. Arrange in an orderly fashion 3 horizontal rows $5,4,2$ mozzarellas in the bag & 11 & \\
\hline & 3. With the end of the bag make a knot & 1 & 1 \\
\hline & 4. Put the bags at the end of the shelf & & 1 \\
\hline \multicolumn{2}{|c|}{ Total technical actions in cycle } & 23 & 2 \\
\hline \multicolumn{2}{|c|}{ Length cycle B [s] } & \multicolumn{2}{|c|}{30} \\
\hline \multicolumn{2}{|c|}{ Pieces produced per day $[\mathrm{n}]$} & \multicolumn{2}{|c|}{180} \\
\hline \multicolumn{4}{|c|}{ C. Putting the ricotta in colanders $(*)$ - One cycle corresponds to the filling of a colander and its placing on the trolley } \\
\hline \multirow{3}{*}{$\begin{array}{l}\text { Technical } \\
\text { actions }\end{array}$} & 1. Collect ricotta on surface with a colander ladle & 3 e 6 & \\
\hline & 2. Fill colanders until they are full & 3 e 6 & \\
\hline & 3. Put colanders on trolley & 1 & 1 \\
\hline \multicolumn{2}{|c|}{ Total technical actions in cycle } & 10 & 1 \\
\hline \multicolumn{2}{|c|}{ Length cycle $\mathrm{C}[\mathrm{s}]$} & \multicolumn{2}{|c|}{15 e 30} \\
\hline \multicolumn{2}{|c|}{ Pieces produced per day $[\mathrm{n}]$} & \multicolumn{2}{|c|}{220} \\
\hline \multicolumn{4}{|c|}{ D. Positioning of mozzarellas on the conveyor belt - One cycle corresponds to the positioning of a mozzarella on the conveyor belt. } \\
\hline \multirow{2}{*}{$\begin{array}{l}\text { Technical } \\
\text { actions }\end{array}$} & 1. Pick up mozzarella & 1 & \\
\hline & 2. Position mozzarella in pre-established position on conveyor belt & & 1 \\
\hline \multicolumn{2}{|c|}{ Total technical actions in cycle } & 1 & 1 \\
\hline \multicolumn{2}{|c|}{ Length cycle D [s] } & \multicolumn{2}{|c|}{2} \\
\hline \multicolumn{2}{|c|}{ Pieces produced per day [n] } & \multicolumn{2}{|c|}{2700} \\
\hline
\end{tabular}

(*) Colanders were made weighing from 0.3 to $1.5 \mathrm{~kg}$, to which correspond respectively 3 and 6 technical actions, so for the total number of technical actions the average was considered (4.5) and also the length of the cycle (22.5).

TABLE 9 - Description of repetitive tasks.

movements and compressions localized in the upper limbs.

As far as concern the work positions examined, the workers expressed a desire to have better work tables, which were more ergonomic, or simply higher, so that they wouldn't have to bend down or carry out movements which require more effort than necessary.

In particular the packing operations are carried out on a table which is rather uncomfortable for operations such as the wrapping of blocks of butter or the packing of mozzarellas.

Organizational interventions have an effect on the ergonomic planning of the work (rhythms, breaks, partial or total rotations of alternating tasks). These changes tend to improve aspects linked to the high frequency and repetitiveness of work movements over prolonged periods, and also the absence or lack of adequate recovery periods.

From the observations made of all the work positions with repetitive actions examined, it emerges that

\begin{tabular}{|c|c|c|c|c|c|}
\hline \multicolumn{2}{|r|}{ Task } & A & B & C & D \\
\hline \multirow{5}{*}{ 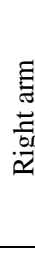 } & Length of task in shift [s] & 5400 & 5400 & 5400 & 5400 \\
\hline & Length of cycle [s] $\left(^{*}\right)$ & 10 & 30 & $15-30$ & 2 \\
\hline & Actions per second [n] & 0,700 & 0.766 & 0.445 & 0.500 \\
\hline & Total actions in task [n] & 3780 & 4136 & 2403 & 2700 \\
\hline & $\begin{array}{l}\text { Total actions in } \\
\text { tasks A, B, C, D }\end{array}$ & \multicolumn{4}{|c|}{$\mathrm{Ae}=13019$} \\
\hline \multirow{5}{*}{ 罢 } & Length of task in shift [s] & 5400 & 5400 & 5400 & 5400 \\
\hline & Length of cycle [s] $(*)$ & 10 & 30 & $15-30$ & 2 \\
\hline & Actions per second $[\mathrm{n}]$ & 0.700 & 0.067 & 0.045 & 0.500 \\
\hline & Total actions in task [n] & 3780 & 361 & 243 & 2700 \\
\hline & $\begin{array}{l}\text { Total actions carried } \\
\text { out in tasks A, B, C, D }\end{array}$ & \multicolumn{4}{|c|}{$\mathrm{Ae}=7084$} \\
\hline
\end{tabular}

(*) Tubs were packed with a weight between 0.3 e $1.5 \mathrm{~kg}$, to which correspond respectively a length of cycle from 15 to 30 seconds, so the average was considered (22.5).

TABLE $\quad 10$ - Calculation of Ae for the left and right arm corresponding to tasks A, B, C, D. 
the right arm is exposed much more than the left. Therefore for the left arm efforts should be made to involve it to a greater extent during repetitive operations.

This might seem a too obvious suggestion, but working gestures which don't require particular precision are often determined by habit rather than incapacity, always using the same arm.

In this specific case there are two asymmetrical tasks: the positioning of the ricotta in the tubs, and the preparation of the bags containing 11 mozzarellas each.

As far as concerns the former, it is clear that the ricotta can be collected from the surface of the multipurpose boiler with either the left or the right hand; all the workers need to do, when they feel any pain in the arm being used, is change position to the other side of the table (where the tubs are waiting to be filled) and use, to carry out the action, the arm which was previously unused. The same is true for the task of packing the mozzarella bags.

It has been seen how the "lack of recovery periods" factor has a clear effect on the final value of the index of exposure. One simple measure, in this context, could be the optimization of the recovery periods: the total time span of the short break (10.00-10.10) is insufficient, but could be redistributed in the shift, maintaining its total duration, with obvious benefits for the worker. For example, half a short break before Task A, and the other half after Task B.

In this way, the number of hours of work carried out without an adequate period of recovery, would drop from 5 to 4 , even if it should be stated that the optimum ratio of work/recovery, which is $5: 1$, is not respected in this case.

Moreover, to reach optimal ratios without damaging productivity is extremely difficult, especially in a sector, such as the dairy sector, in which the timing of given operations is absolutely essential.

It is also advisable to introduce a greater work rotation among the workers.

The tasks which require repetitive technical actions should not, and do not, need to be carried out by the same worker. It is therefore advisable to alternate when possible a task with a high level of repetitivity (such as the task of placing the mozzarellas on the conveyor belt) with a low repetitivity task or another task which is non- repetitive (sanification operations, which take up most of the working afternoon and involve workers who normally never carry out the previously described repetitive tasks).

Training and information programmes regard the awareness of risks, learning how to concretely carry out working gestures, and the use of techniques and suggestions concerning breaks.

From the careful analysis of the work positions and action carried out, it emerges that the speed of the conveyor belt is such that it makes it difficult for the worker to put the mozzarellas in their right places, without missing one out every now and then or without exposing workers to excessive fatigue (and an obvious loss of productivity).

Therefore the workers were shifted to a new position opposite the conveyor belt, with the trolley, on which are deposited the mozzarellas which need to be wrapped, next to the worker (fig. 5).
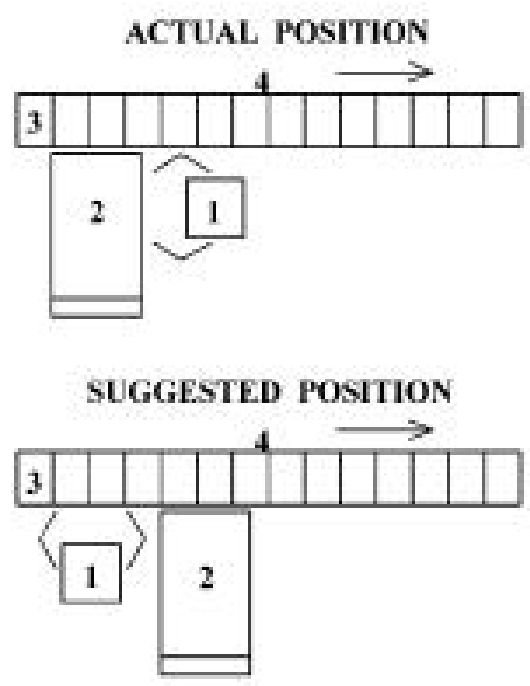

1) worker; 2) trolley; 3) pre-established position of mozzarella; 4) conveyor belt.

Fig. 5 - Actual and suggested position.

\begin{tabular}{|l|c|c|c|c|c|c|c|c|}
\hline & \multicolumn{9}{|c|}{ Right arm } & \multicolumn{4}{c|}{ Left arm } \\
\hline Task & A & B & C & D & A & B & C & D \\
\hline CF & 30 & 30 & 30 & 30 & 30 & 30 & 30 & 30 \\
\hline Ff & 1.00 & 1.00 & 0.75 & 1.00 & 1.00 & 0.85 & 1.00 & 1.00 \\
\hline Fp & 1.00 & 0.50 & 0.30 & 0.70 & 1.00 & 0.70 & 1.00 & 0.70 \\
\hline Fc & 1.00 & 1.00 & 0.90 & 0.95 & 1.00 & 1.00 & 1.00 & 0.95 \\
\hline Duration of task [min] & 90 & 90 & 90 & 90 & 90 & 90 & 90 & 90 \\
\hline Summation & 2700 & 1350 & 546 & 1795 & 2700 & 1606 & 2700 & 1795 \\
\hline Fr & \multicolumn{9}{|c|}{0.45} & & & \multicolumn{5}{c|}{0.70} \\
\hline Ar & \multicolumn{9}{|c|}{2875} \\
\hline
\end{tabular}

TABLE $11-$ Calculation of Ar for the left and right arm in correspondence to the tasks A, B, C, D. 
In this way not only can time be saved while carrying out repetitive tasks, but technical actions carried out in a minute can be halved (from 30 to 15 actions per minute carried out by each arm). This suggestion was welcomed by the workers.

The fairly obvious hypothesis, of lowering the speed of the conveyor belt, would never receive a favorable response from the employers, since it would necessarily involve a loss of productivity, in spite of a reduction of fatigue for the workers.

By the end of the work shift, or at least during the same working day, all the mozzarellas have to be wrapped, since during the following morning they will be put into their bags and sent off to be sold. It is impossible to prolong the packing times of such products.

\section{Acknowledgments}

Research carried out with MIUR PRIN 2005 funds, titled "Analysis of the applicability and extent of workers safety norms and of the quality and safety of food products: studies for some processing factories", national coordinator Prof. G. Zoppello.

\section{References}

[1] ACGIH, Ergonomics, Statement on work-related musculo-skeletal disorders, Hand Activity Level, (2001), Proceedings of Cincinnati Meeting, Ohio

[2] Anderson V.P., Cumulative trauma disorders: a manual for muscolo-skeletal diseases of the upper limb, (1988), Taylor and Francis.

[3] Armstrong T.J., Ulin S., Analysis and design of jobs for control of work-related upper limb disorders, (1995), M.H. Hunter.

[4] Colombini D., Occhipinti E., FAnTI M., Il metodo OCRA per l'analisi e la prevenzione del rischio da movimenti ripetuti, (2005), Franco Angeli.
[5] Colombini D., Occhipinti E., Grieco A., Risk assessment and management of ripetitive movements and exertions of upper limbs: job analysis, OCRA risk index, prevention strategies and design principles, (2002), The Netherlands Elsevier.

[6] Hagberg M., Silverstein B., Wells R., Work-related musculoskeletal disorders. A reference book for prevention, (1995), Taylor and Francis.

[7] European Agency for Safety and Health at Work, Repetitive Strain Injuries in the Member States of the European Union: The results of an information request, (2000), Office for Official Publications of the European Communities.

[8] SCHNEIDER S., OSHA's draft standard for prevention of work-related musculo-skeletal disorders, (1995), Applied Occ. Environ Hygiene.

\section{SUMMARY}

For the health of workers it is necessary to consider, together with traditional risks (noise, vibrations, microclimate etc.), risks deriving from repetitive movements, which can generate muscolo-skeletal disorders.

These risks can be found in artisan dairies, where the limited use of machinery and the rapid successive passages for processing the milk require high-frequency repetitive manual movements.

The study analysed the risks of repetitive movements for workers in a dairy, using the OCRA method. Various risk-involving operations emerged, which require the re-planning of the workplace. The proposed interventions have not involved high costs for the dairy, or a loss of productivity.

Key words: dairy, musculoskeletal disorders, Ocra method. 
